\title{
Observation Outcome Relationship
}

National Cancer Institute

\section{Source}

National Cancer Institute. Observation Outcome Relationship. NCI Thesaurus. Code C70776.

The relationship between two or more observation outcomes. It might refer to a diverse range of relationships such as temporal, or sequential, or indicate that a test was performed to verify another test result, or designate that a test is a component of a test panel. 